\title{
El diccionario escolar y algunas de las problemáticas que surgen en su elaboración'
}

\author{
The school dictionary and some of the issues that \\ come up during its elaboration
}

\author{
Viviana Mahecha Mahecha \\ María Betulia Pedraza Pedraza
}

\section{Resumen}

Las últimas tendencias de la lexicografía didáctica ponen de manifiesto la necesidad de reflexionar sobre la importancia del diccionario escolar como una herramienta de aprendizaje no solamente lingüístico, sino también contextual, es decir, como una fuente de conocimiento de sus usuarios potenciales, en este caso, maestros y estudiantes de los distintos niveles escolares. Este texto propone una revisión de algunos criterios tenidos en cuenta para la elaboración de tres diccionarios escolares básicos ofrecidos en el mercado lexicográfico colombiano, a fin de evidenciar problemáticas internas y externas que pueden desvirtuar la naturaleza didáctica de estos últimos y su relación con los contextos reales de sus usuarios.

Palabras clave

Diccionario escolar, lexicografía didáctica, pedagogía, microestructura, macroestructura.

\section{Abstract}

The last trends of didactic lexicography demonstrate the need to think about the importance of the school dictionary as a tool for learning not only linguistically but also contextually, that is to say, as a source of knowledge for its potential users, in this case, teachers and students of different school levels. In agreement with the previous idea, this text proposes a review of some criteria taken into account for the production of three basic school dictionaries offered to the lexicographical Colombian market. The internal and external problems that could jeopardize the didactic nature of the dictionary and its relationship with the real contexts of its users are considered.

Keywords

School dictionary, didactic lexicography, pedagogy microstructure, macrostructure.

Artículo recibido el 25 de febrero de 2009 y aprobado el 28 de abril de 2009.

1 Ponencia presentada en el XXV Congreso Nacional de Lingüística, Literatura y Semiótica. Medellín, 24,25 y 26 de septiembre de 2008.

2 Profesoras del Departamento de Lenguas de la Universidad Pedagógica Nacional. Correo electrónico: vivianamahecha@hotmail.com 
¿Hay algo más racional que un diccionario? Por poco que se lo lea aparte de consultarlo, el diccionario informa, instruye, incluso enseña; sin largos discursos, sin retórica vana, distribuye sobria, democráticamente el saber a quien lo solicite. Pues bien, este objeto robusto e incluso simplista -si pensamos en la maraña de los hechos, las nociones, las sustancias de las que está hecho el mundo-, pone en juego sin decirlo (nada menos locuaz que un diccionario) los problemas más graves, los más candentes, y acaso también los más vertiginosos que la mente humana haya llegado a conocer y a debatir.

Roland Barthes

\section{El diccionario escolar como fuente de conocimiento y herramienta pedagógica}

En la actualidad, son muchas las definiciones planteadas sobre el término diccionario. Para unos, es el instrumento que proporciona información sobre el uso correcto de la lengua, para otros, es un producto cultural e histórico (Porto, 2002), y para algunos, (Maldonado, 2000) la solución a una duda de cualquier tipo:

El adolescente que busca a escondidas el significado de palabras tabú; el niño que se ríe a carcajadas, de puro nerviosismo, al ver así, escritas con todas las letras, los nombres de esas realidades escatológicas que tanto le atraen; el poeta ripioso a la búsqueda de la rima perdida, el creador literario en lucha consigo mismo para conseguir encontrar la palabra precisa; el enfermo aprensivo, perdido entre enciclopedias que sólo consiguen aumentar su angustia por saber si la medicina tiene solución para ese problema suyo... [...] Poeta, novelista, enfermo y adolescente (entre muchos otros), todos tienen en común el viaje iniciado: la búsqueda, en un libro, a la solución de una duda, no siempre de carácter exclusivamente lingüístico, sino, tan a menudo, de carácter incluso vital (p. 117).

En general, las definiciones anteriores coinciden en afirmar que el diccionario es una fuente de conocimiento, bien sea sobre la lengua y su uso responsable, aspectos sociales e históricos, o acerca de los múltiples contextos en los que se encuentran inmersos sus usuarios reales. Esto último supone una articulación de este tipo de texto con procesos de enseñanza y aprendizaje, los cuales se funda- mentan en la construcción de diversas clases de conocimiento sobre el mundo que, a su vez, pueda ser comunicado para un otro. En otros términos, el diccionario se presenta, en el contexto escolar, como una herramienta que permite a los usuarios, además de acceder a nuevas realidades, desarrollar competencias comunicativas para recrear estas últimas mediante diferentes tipos de discurso: oral, escrito, formal, informal, etc.

En este orden de ideas, el diccionario es un instrumento que, además de servir para decodificar la realidad de los hablantes, sirve para codificarla. Su doble función constituye una verdadera fuente de posibilidades pedagógicas. Es justo aquí, cuando el papel que desempeña el profesor como promotor de las múltiples ventajas y usos que ofrece el diccionario se convierte en fundamental, dado que, sin la orientación adecuada, resultaría muy poco provechoso acceder a este compendio sin otra razón más que para decodificar una entrada desconocida, relegando de esta manera otros importantes papeles que le competen al diccionario. Así lo señala Prado (2000) al referirse al papel que ha de desempeñar el profesor de lengua como el responsable de enseñar a los estudiantes la utilización de un instrumento de acceso al conocimiento.

El profesor ha de conocer entonces que el diccionario no sólo sirve para buscar el significado de las palabras, sino que su uso es de vital importancia en el desarrollo de una competencia lingüística suficiente para mantener una adecuada interacción comunicativa en todos los espacios de la vida del individuo. Por lo general, estos compendios no se acompañan de guías didácticas dentro del aula, $y$ cuando lo hacen, muchas veces éstas no responden a las posibilidades didácticas que tiene el diccionario, por el contrario, proponen actividades aisladas que no se relacionan con el contenido ni con las características técnicas que este tipo de texto presenta.

\section{La lexicografía didáctica}

Teniendo en cuenta las definiciones del diccionario escolar como fuente de conocimiento y herramienta pedagógica, así como las implicaciones que estas afirmaciones suscitan, conviene anotar que éste 
constituye el objeto de estudio de la lexicografía didáctica. El interés de dicho campo de conocimiento ha sido, además de reflexionar sobre la naturaleza de este tipo de diccionarios, proporcionar elementos para su análisis crítico, teniendo en cuenta las problemáticas que los diccionarios escolares pueden evidenciar en su afán de ser comercializados en el mundo editorial 1 .

Es decir, el estudio sobre los criterios de elaboración y análisis de este tipo de diccionarios supone el planteamiento de teorías y metodologías que permitirán cada vez más dar cuenta de sus problemáticas, requerimientos de sus usuarios y la importancia de establecer relaciones más estrechas con los tipos de enseñanza y aprendizaje. A propósito de las aspiraciones de la lexicografía didáctica, Hernández (2000) afirma:

[...] que la lexicografía didáctica debe tender a la sistematicidad, que en el futuro deberán programarse muy bien cuáles habrán de ser los sistemas de diccionarios más convenientes y cuáles las series más apropiadas, y que para todo eso es imprescindible que se continúe investigando, como ya ha empezado a hacerse, para determinar cuáles son las verdaderas necesidades de los distintos grupos de usuarios (p. 106).

Por otra parte, este tipo de lexicografía demanda la interrelación de saberes no solamente lingüísticos, sino también pragmáticos, sociolingüísticos y, sobre todo, didácticos que hacen de estos diccionarios un objeto de estudio muy particular. Desde esta perspectiva se inscribe el análisis comparativo que se hará más adelante sobre tres diccionarios escolares, cuya finalidad es examinar algunas de las problemáticas externas y técnicas que se presentan en su elaboración, y así brindar orientaciones a padres, profesores y estudiantes, definidos como sus usuarios potenciales.

1 A propósito de las problemáticas relacionadas con estos diccionarios, debe señalarse que durante mucho tiempo se consideró que su elaboración consistía simplemente en reducir el vocabulario y las acepciones de los diccionarios generales de lengua, es decir, era solamente una adecuación de volumen.

\section{Los diccionarios escolares y su tipología}

Una de las tareas de la lexicografía didáctica consiste en lograr una mayor y mejor propuesta de series de diccionarios escolares, es decir, evidenciar las diferencias existentes entre diccionarios que comparten un mismo género (didáctico) de acuerdo con las adecuaciones que deben experimentar en el manejo de la información lingüística y cultural según la serie y el grupo de destinatarios respectivos, los cuales pertenecen a niveles educativos distintos.

De acuerdo con Prado (2000), "es evidente que no todos los diccionarios son iguales ni sirven para obtener la misma información y que no todos los diccionarios son adecuados para todo el mundo [...]" (p. 174). Así, existe una gran variedad de obras lexicográficas con características diferenciadoras frente a las cuales un usuario real debe elegir aquella que más le conviene en relación con sus necesidades de consulta. Esta autora plantea una extensa tipología de diccionarios ${ }^{2}$, pero, particularmente en la relación profesor-estudiante, sugiere las siguientes clases y características:

\section{Vocabularios o diccionarios infantiles (de cero a ocho años)}

Estos compendios deben desarrollar aspectos como la lateralidad, memoria visual y elementos del proceso de lectoescritura. Por consiguiente, requieren la inclusión de una tipografía adecuada, gran variedad de ilustraciones $y$, sobre todo, un vocabulario reducido.

\section{Diccionarios escolares (de ocho a doce años)}

Sus destinatarios son estudiantes de primaria y algunos años iniciales de secundaria y, por tanto, su diseño debe basarse en criterios didácticos acordes con los niveles educativos y edades de sus usuarios.

\section{Los diccionarios para la enseñanza de la lengua, diccionarios de uso y diccionarios normativos (de doce a dieciséis años).}

En este caso se debe proponer un léxico usual, notas sobre la pronunciación, definiciones comprensibles,

2 Aquí se tendrá en cuenta su clasificación de acuerdo con la edad y nivel de conocimiento del usuario (0p. cit., p.186). 
abundantes ejemplos e información de tipo gramatical y normativo, sinónimos y antónimos, y apéndices que complementen y aclaren elementos contenidos en el cuerpo del diccionario. Finalmente, la autora en mención señala "una etapa posobligatoria" (p.188), en la que sugiere la consulta de diccionarios específicos, como los ideológicos, etimológicos, técnicos, etc.

\section{Criterios para elegir un diccionario escolar y algunas falsas creencias al respecto}

Aun cuando la crítica lexicográfica ha establecido algunos parámetros de valoración sobre diccionarios escolares, Maldonado (2000, p. 126) afirma que no puede precisarse un único método de valoración, sólo unos juicios generales, en tanto cada usuario es quien debe proponer el suyo, de acuerdo con sus necesidades de consulta. Sin embargo, es habitual que un usuario lleve a cabo las siguientes reflexiones a la hora de elegir un diccionario, las cuales muchas veces obedecen a algunas falsas creencias sobre este último:

El diccionario es un libro de consulta que va cambiando en proporcionalidad directa con los cambios que se generan en el sistema de la lengua, los cuales deben ser registrados en los compendios y, en el caso de los diccionarios sincrónicos, deben suprimirse aquellos vocablos caídos en desuso. Sin embargo, muchas veces se tiende a considerar como criterio de elección el que el mejor diccionario es aquél que se "usa en la casa", o, peor aún, el que ha sido usado de generación en generación.

Por otra parte, algunos consideran que todos los diccionarios son iguales, pero no es así, dado que cada uno presenta unas características que lo que hacen especial en cuanto al contenido que presenta y al tipo de usuarios al que va dirigido. Por estas razones, no es aconsejable adquirir un diccionario general para que un niño en etapa escolar lo consulte, en tanto la visión con la que se elabora este tipo de compendios es la de unos usuarios que manejan un léxico más elevado y no un léxico básico en proceso de enriquecimiento y ampliación.

Por otro lado, otros usuarios suponen que si el diccionario incluye un número elevado de voces es un buen diccionario; sin embargo, esta afirmación no es lo suficientemente confiable, en tanto una obra lexicográfica determina su calidad teniendo en cuenta elementos como la pertinencia del léxico incluido en relación con el destinatario, la funcionalidad de los ejemplos allí mostrados, la claridad de las definiciones, entre otros.

\section{Hacia una propuesta de criterios para elegir un diccionario escolar}

Luego de revisar algunas propuestas en torno a los aspectos que deben tenerse en cuenta para elaborar y asimismo elegir un diccionario escolar ${ }^{3}$, se enlistan una serie de criterios que guardan relación con características externas e internas o técnicas de éste. En su mayoría, se tienen en cuenta aquellos dados por Garriga (2002) en su intento por suministrar al usuario del diccionario escolar herramientas para evaluar su carácter didáctico. A continuación, se exponen de manera muy general la naturaleza de los veinte criterios de base para el análisis valorativo de tres diccionarios básicos, entre los cuales se encuentran el Diccionario Escolar Larousse, del (2007), el Diccionario Didáctico Escolar, didec (2008) y el Diccionario Escolar Ilustrado Color, deic (2004).

\section{Características externas}

\section{Formato y encuadernación}

Este criterio encierra características que, aunque pueden ser vistas como subsidiarias al contenido de un compendio lexicográfico, cuando se refieren al diccionario escolar, constituyen rasgos que adquieren especial importancia en tanto este tipo de texto debe ser liviano y funcional, teniendo en cuenta el desplazamiento (casa-colegio) que pueda hacer su usuario. Además, el papel, por ejemplo, debe ser resistente y adecuado para ser leído.

\section{Título e informaciones externas}

Este apartado conlleva aspectos que responden a elementos de presentación de la obra, los cuales se encuentran en dos guardas y el lomo. El título

3 Pueden consultarse algunos criterios dados por Hernández (1989, p. 124), Martínez (1991, p. 61), Maldonado (2000, p. 124), entre otros. 
del diccionario revela el tipo de usuario al que va dirigido, y las informaciones externas que el usuario puede encontrar en él, así como la utilidad que le puede suministrar. Sin embargo, muchos de los títulos o adjetivos que se encuentran acompañando los términos "diccionarios escolares" (básico, ilustrado, esencial, abreviado, etc.) no guardan relación con lo ofrecido en el contenido en estos diccionarios.

\section{Responsables de la obra}

La labor lexicográfica no es un ideal que se pueda llevar a cabo por una sola persona; de allí la importancia que adquiere la conformación de equipos lexicográficos, en tanto sólo a partir de su formación y organización es posible dar cuenta de un producto lexicográfico de calidad.

\section{Editorial}

Este es un criterio que cobra especial trascendencia cuando de la compra de diccionarios se trata, en tanto la tradición y el prestigio de algunas editoriales supedita a los usuarios a comprarlos. Sin embargo, no deben perderse de vista las bondades que puedan ofrecer otras propuestas editoriales que no sean altamente reconocidas.

\section{Presentación}

Es necesario que los diccionarios contengan un apartado en sus primeras páginas acerca de lo que contienen, de la manera en que se debe aprovechar su contenido y cómo se puede acceder a él. Es justo en este punto en el que es posible identificar inicialmente las ventajas o desventajas de la obra lexicográfica.

\section{Tipografía}

Esta es una característica muy importante en los diccionarios escolares. El tipo y tamaño de la letra marca la diferencia entre lo que puede facilitar o dificultar la búsqueda de los términos, por esto las letras de buen tamaño y con colores que permitan diferenciar la entrada del artículo lexicográfico constituyen un aspecto visual importante, en tanto le ofrecen al usuario una posibilidad de búsqueda más sencilla y llamativa.

\section{Características técnicas Macroestructura}

\section{Número y selección de voces}

La incorporación de un número determinado de entradas es un indicador para valorar negativa o positivamente un ejemplar lexicográfico, sin embargo, esto no quiere decir que un buen diccionario sea el que contenga más voces, sino que, además de esto, haya seleccionado términos usuales y, sobre todo, en relación con los contextos del usuario.

\section{Entradas}

El tratamiento de la entrada está supeditado a condiciones como la flexión y su organización siguiendo el orden alfabético. La lematización dependerá de criterios que determinan si la flexión de género se propone en la misma entrada o si se mantiene por separado. Veamos algunos casos:

actor, triz m. y f. Artista de una obra de teatro o de un film. ||Persona que toma parte activa en algo.

reina f. Esposa del rey. ||La que ejerce la potestad real por derecho propio. ||Pieza del juego de ajedrez, la más importante después del rey. ||

rey $\mathrm{m}$. Monarca o príncipe soberano de un Estado

(DEL-LAROUSSE)

actor (ac.<tor $>$ ) [sustantivo masculino] Hombre que representa un papel en el teatro o en el cine. || [El femenino es «actriz».]|| Sinónimos: comediante.

actriz $($ ac $<<$ triz $>)$ [sustantivo femenino]Mujer que representa un papel en el teatro o en el cine. || [E] masculino es «actor». Su plural es «actrices».] || Sinónimos: comediante.

(DIDEC-SM)

\section{llustraciones}

Este criterio no debe responder a una inclusión caprichosa, sino a una necesidad real, es decir, que una foto o un dibujo debe cumplir con la función de ampliar la información suministrada por la definición. 


\section{Calidad de las definiciones}

Una definición debe caracterizarse por dar información que resulte útil para el usuario, es decir, que pueda resolver su duda evitando el recorrido por varias secciones del diccionario sin encontrar una respuesta favorable a su requerimiento. Lo anterior supone que una definición no debe ser circular ni presentar pistas perdidas y, además, debe guardar relación con el tipo de diccionario en el que se inscribe, para que su formulación discrimine entre la utilización de un léxico básico o uno más elevado.

Los ejemplos presentados a continuación muestran casos de pistas perdidas:

tradicionalista adj. y s. partidario del tradicionalismo. ||Carlista.

"carlista" no aparece registrado en el diccionario. hediondo, da adj. Pestilente. pestilente adj. Pestífero.

"pestífero" no aparece registrado en el diccionario

(DEL-LARousse)

Por su parte, esto ejemplos señalan definiciones circulares.

herrín m. y herrumbre f. Orín. orín m. Herrumbre.

desacuerdo $\mathrm{m}$. Disconformidad.

disconformidad f. Desacuerdo

(DEL-LARousSE)

\section{Microestructura Acepciones}

Las acepciones deben estar ordenadas de manera sistemática en el diccionario, preferiblemente bajo un criterio de uso, sin excluir aquellas de uso frecuente ni generales. Además, deben evidenciar una fácil localización en el artículo lexicográfico. En este caso, obsérvese un tipo de ordenamiento de acepciones de lo más general a lo más específico sobre el siguiente sustantivo:

acción $($ ac· $<$ ción $>)$ [sustantivo femenino] 1 Lo que se hace: Ayudar al que lo necesita es una buena acción. 2 Influencia o efecto producidos por algo: En esos troncos hechos cenizas se ve la acción del fuego. 3 Conjunto de los hechos que forman el argumento de una película o de otra obra: La acción de la novela se sitúa en una isla. 4 Cada una de las partes en que se divide el dinero de una empresa: Compró acciones de esa fábrica. ||Sinónimos: 1 acto, hecho, obra.

(DIDEC-SM)

\section{Ejemplos}

Es quizás uno de los elementos más importantes de los diccionarios escolares debido a su función didáctica. Éstos deben completar información dada en la definición e ilustrar de manera contextual elementos de uso y aspectos gramaticales específicos. En la actualidad, muchos diccionarios carecen de este elemento y otros lo han propuesto para ilustrar la mayoría de sus acepciones:

deber (de-<ber $>$ ) y [sustantivo masculino] 1 Lo que se tiene obligación de hacer: Tu deber es aprender. y [verbo] 2 Tener la obligación de hacer algo o de ser de determinada manera: Debes lavarte los dientes. 3 Tener la obligación de dar una cantidad de dinero por haber recibido algo: Me debes cinco mil pesos. y deberse $\mathbf{4}$ Ser consecuencia: Mi debilidad se debe a la falta de vitaminas. 5 exp. || hacer el deber Proponerse hacer algo de forma firme: Voy hacer el deber de visitar más a mis abuelos. || Sinónimos: 3 adeudar.

|| Contrarios: 3 pagar.

(DIDEC-SM)

viable adj. Que puede vivir: una criatura viable. ||Fig. Realizable.

(DEL-LAROUSSE)

\section{Información gramatical}

Según Garriga (2000, p. 9), es importante que se den categorías gramaticales a propósito de plurales irregulares, conjugaciones verbales, preposiciones, tipos de verbos, etc., y que se presenten en el artículo lexicográfico de manera clara y sencilla para el lector, es decir, que no saturen a este último de marcas 
gramaticales complejas o de difícil comprensión. Obsérvese el tratamiento de la información gramatical en los siguientes diccionarios:

esparcir. tr. y prnl. Extender lo que está junto o amontonado. 2. Difundir una noticia. 3. Distraer.

(DEIC-NORMA)

bebido, da (be $<$ bi $>$ do, da) [adjetivo o sustantivo] 1 Dicho de una persona, que está bajo los efectos del alcohol que tomó. [sustantivo femenino] 2 Líquido que se bebe: El agua es la bebida más natural. || Sinónimos: 1 borracho. || Contrarios: 1 sobrio.

(DIDEC-SM)

\section{Información sobre el uso}

En un diccionario escolar es importante ofrecerle al lector información sobre restricciones pragmáticas, estilísticas, temporales, dialectales, etc. Las marcas pragmáticas en especial se convierten en un referente de uso para el lector que, como se ha dicho antes, puede consultar en un diccionario información precisa para comunicarse adecuadamente. Al parecer, esta información no se incluye en muchos de los diccionarios escolares o, si se hace, es de manera asistemática. Un caso en el que se carece de esta marca es:

clavar tr. Introducir a golpes un clavo o un objeto puntiagudo en un cuerpo o superficie. 2. Asegurar con clavos una cosa en otra. 3. try prnl. Engañar a alguien o estafarle cobrándole más de lo justo.

(DEIC-NORMA)

\section{Expresiones}

La gran mayoría de los diccionarios escolares excluye este tipo de unidades que pueden registrar usos frecuentes de la lengua. Es importante que cada diccionario defina sus criterios de localización al usuario. Ejemplo:

laurel $($ lau $\cdot<$ rel $>$ ) [sustantivo masculino] 1 Árbol con las hojas alargadas y terminadas en punta, que se usan para dar sabor a la comida. 2 exp. || dormirse en los laureles Reducir el esfuerzo porque se confía en lograr el éxito: Si quieres ganar este año, no te duermas en los laureles y estudia mucho. ॥ [La expresión es coloquial.]

(DIDEC-SM)

\section{Sinónimos y antónimos}

Esta información es útil en la medida en que enriquece el vocabulario. Los sinónimos y antónimos deberían aparecer por cada acepción y asimismo señalar si son equivalentes contextuales:

lacio, cia (<la $>$ cio, cia) [adjetivo] Dicho del cabello, que es liso y cae sin formar ondas ni rizos. || Sinónimos: liso. || Contrarios: crespo.

(DIDEC-SM)

\section{Etimologías}

Es un elemento poco usado en los diccionarios escolares en tanto la ausencia de los étimos no condiciona el uso de un término; sin embargo, en algunos de ellos puede dar información sobre extranjerismos. Obsérvese esta información:

script m. (pal. ingl.). Tipo de letra impresa semejante a la escritura manual.

soufflé [sufflé] adj. y s. m. (pal. fr.). Dícese de un plato de consistencia esponjosa preparado en el horno.

(DEL-LARousse)

\section{Apéndices}

Es una parte del diccionario en la que se puede dar información contextual (mapas, símbolos, capitales, etc.) o gramáticas que pueden complementar información dada en el cuerpo del diccionario. Los apéndices deben tener una relación estrecha con los entornos de uso y académicos del estudiante, es decir, información útil.

\section{Contenidos ideológicos}

De acuerdo con Maldonado (2000, p. 125), es necesario examinar el contenido ideológico de los diccionarios. Son muchas las valoraciones subjetivas que en su gran mayoría se hacen en la construcción de definiciones y ejemplos. Este rasgo debe ser eva- 
luado cuidadosamente, en especial en la elaboración de diccionarios escolares:

dios $\mathrm{m}$. Ser supremo y creador del universo

(DEL-LaRousse)

\section{Orientaciones didácticas}

Este criterio consiste en un tipo de recurso que acompaña el diccionario escolar, el cual comprende una gama de actividades que permite aprender a usar el diccionario. Esta herramienta orienta a pro- fesores y estudiantes sobre la exploración didáctica del diccionario en el aula de clase. Es un criterio novedoso que garantiza funciones de codificación en los usuarios potenciales de estos diccionarios. Son escasos los diccionarios que se acompañan de guías didácticas.

\section{Análisis comparativo}

A continuación se presentan las directrices de los cuadros de análisis que se tendrán en cuenta más adelante:

\begin{tabular}{|c|c|}
\hline \multicolumn{2}{|c|}{ Características externas } \\
\hline 1 & Formato y encuadernación \\
\hline 2 & Título e informaciones externas \\
\hline 3 & Editorial \\
\hline 4 & Responsable(s) de la obra \\
\hline 5 & Presentación \\
\hline 6 & Tipografía \\
\hline v & Valoración final \\
\hline \multicolumn{2}{|c|}{ Características técnicas } \\
\hline \multicolumn{2}{|c|}{ Macroestructura } \\
\hline 7 & Número y selección de las voces \\
\hline 8 & Entradas \\
\hline 9 & Ilustraciones \\
\hline v & Valoración final \\
\hline \multicolumn{2}{|c|}{ Microestructura } \\
\hline 10 & Calidad de las definiciones \\
\hline 11 & Acepciones \\
\hline 12 & Ejemplos \\
\hline 13 & Información gramatical \\
\hline 14 & Información sobre el uso \\
\hline 15 & Expresiones \\
\hline 16 & Sinónimos y antónimos \\
\hline 17 & Etimología \\
\hline 18 & Apéndices \\
\hline 19 & Contenidos ideológicos \\
\hline 20 & Orientaciones didácticas \\
\hline v & Valoración final \\
\hline
\end{tabular}

\section{Diccionario Escolar Larousse, DEL}

1 Es un ejemplar de peso liviano, de pequeño volumen, de empaste colorido (rojo de cartón plastificado flexible). Su presentación se hace en papel periódico.

En el título se señala que es un tipo de diccionario escolar, pero en el prólogo se registra como Diccionario Escolar Manual de

2 Consulta. En la cubierta posterior se registra el nombre de la editorial, el número de voces, acepciones, ilustraciones e insertos. Se especifica el grado de enseñanza al que está dirigido (educación básica). 


\begin{tabular}{|c|c|}
\hline 3 & Ediciones Larousse. \\
\hline 4 & $\begin{array}{l}\text { Se registra un solo editor y se asume que la realización editorial está bajo su responsabilidad. No hay nombres de diseñadores } \\
\text { ni de diagramadores. }\end{array}$ \\
\hline 5 & $\begin{array}{l}\text { Las partes introductorias son: presenta prólogo escrito por el editor ( } 1 \text { pág.). Presenta abreviaturas usadas ( } 1 \text { pág.). Presenta } \\
\text { muy pocas indicaciones sobre el manejo del diccionario ( } 1 \text { pág.). No hay ilustraciones que acompañen las indicaciones de uso; } \\
\text { se incluyen algunos signos que muestran la separación de acepciones. }\end{array}$ \\
\hline 6 & $\begin{array}{l}\text { Tiene un tamaño de letra muy pequeño que dificulta la lectura y la búsqueda. El lema se registra en negrita para facilitar su } \\
\text { búsqueda. En los bordes superiores izquierdo y derecho de las páginas se registra el cambio del orden alfabético de los lemas, } \\
\text { mediante la inclusión de sílabas. }\end{array}$ \\
\hline V & $\begin{array}{l}\text { La tipografía no es la más adecuada para un niño, dado que el tamaño de la letra se constituye en una de las principales } \\
\text { barreras para poder acceder al contenido. De otra parte, se muestra como un punto favorable su tamaño y peso. }\end{array}$ \\
\hline 7 & $\begin{array}{l}\text { De acuerdo con la información que presenta el diccionario contiene más de } 35000 \text { palabras y más de } 100000 \text { significados, } \\
\text { frases y ejemplos; además de contener palabras del español actual, neologismos, tecnicismos y americanismos. Cabe anotar } \\
\text { que este ejemplar contiene en su corpus escasos lemas del español actual utilizado por un estudiante de educación básica. } \\
\text { Presenta una cantidad considerable de americanismos y de españolismos que no hacen parte del contexto de uso del niño. }\end{array}$ \\
\hline 8 & $\begin{array}{l}\text { No presenta entradas distintas para mostrar la flexión, señalándola por medio de la flexión de género silábica, y en el caso de } \\
\text { femeninos irregulares se pone la moción al frente y en otros casos el lema se presenta separadamente. En el caso, de los lemas } \\
\text { dobles, aparecen en la misma entrada. En cuanto al manejo de la homonimia, cabe señalar que las acepciones van separadas } \\
\text { por una barra doble dentro del mismo artículo lexicográfico. En cuanto al orden alfabético, las entradas se presentan acudiendo } \\
\text { a los parámetros de inclusión de ch en c y de II en I. }\end{array}$ \\
\hline 9 & $\begin{array}{l}\text { La inclusión de ilustraciones se hace mediante apéndices de dibujos y esquemas que se encuentran en medio y en la parte } \\
\text { final del diccionario, pero que no hacen parte del contenido de los artículos lexicográficos ni señala remisión alguna, los cuales } \\
\text { algunas veces resultan poco útiles (apéndice de figuras planas, volúmenes, unidades de medida anglosajonas, máquinas } \\
\text { simples). De igual forma, se incluyen dibujos sobre anatomía. }\end{array}$ \\
\hline V & $\begin{array}{l}\text { Es un diccionario que presenta un corpus de palabras que no se ajusta a los requerimientos de sus usuarios, en tanto no forma } \\
\text { parte de su realidad lingüística ni contextual. Escasean acepciones coloquiales, así como tecnicismos propios de los usos reales } \\
\text { y, en su lugar, se incluyen términos cultos. }\end{array}$ \\
\hline 10 & $\begin{array}{l}\text { Presenta pistas perdidas y definiciones circulares. Hay presencia de definiciones enciclopédicas. En algunos casos se vale del } \\
\text { entorno para definir. Por otra parte, presenta definiciones que son ampliadas mediante paréntesis. }\end{array}$ \\
\hline 11 & $\begin{array}{l}\text { No hay claridad en torno al número de acepciones. Las acepciones van separadas por medio de una barra doble. Las } \\
\text { acepciones se organizan de la más general a la más específica. En cuanto a los alcances que algunos lemas pueden tener, cabe } \\
\text { anotar que presenta algunas extensiones semánticas de algunas entradas. De igual manera, presenta marcas de transición } \\
\text { semántica. }\end{array}$ \\
\hline 12 & Aunque hay riqueza en ejemplos, muchos de ellos no pertenecen a la realidad social y cultural de los destinatarios. \\
\hline 13 & $\begin{array}{l}\text { Existen marcas gramaticales que no corresponden con las abreviaturas propuestas o que simplemente no están contenidas en la } \\
\text { lista que propone el diccionario, lo que las hace complejas en su comprensión. }\end{array}$ \\
\hline 14 & $\begin{array}{l}\text { En este apartado presenta marcas de uso, pero no son frecuentes. Entre las más comunes está la correspondiente a "familiar". } \\
\text { Presenta marcas diatópicas que hacen referencia principalmente a gentilicios, cuya utilidad no es muy clara para el usuario. Por } \\
\text { otra parte, presenta marcas de transición semántica o estilística mediante la inclusión, como es el caso de la marca "figurado". }\end{array}$ \\
\hline 15 & $\begin{array}{l}\text { No es claro el criterio que se usa para la inclusión de las expresiones, en tanto no se señala la frase mediante negrita o } \\
\text { mediante el uso de algún color; además, el uso generalizado de cursiva para los ejemplos, usos figurados y frases no permite } \\
\text { diferenciar con facilidad unos de otros. }\end{array}$ \\
\hline 16 & No presenta sinónimos ni antónimos. \\
\hline 17 & Propone etimologías para los extranjerismos e incluye unos paréntesis de pronunciación. \\
\hline 18 & $\begin{array}{l}\text { Se registra un apéndice que contiene láminas a color sobre sistemas fisiológicos y un mapa sobre la difusión del español. De } \\
\text { igual manera, en este apartado se ubica la guía didáctica y las orientaciones sobre qué es una entrada y un artículo y lo que } \\
\text { contiene cada uno. }\end{array}$ \\
\hline 19 & Hay ciertas valoraciones subjetivas que impregnan los contenidos de rasgos ideológicos. \\
\hline 20 & Presenta orientaciones didácticas en torno a la manera en que se debe hacer la búsqueda. \\
\hline
\end{tabular}


Aunque presenta abundantes ejemplos, éstos no ilustran la realidad de los usuarios a quienes va dirigido; además, propone definiciones circulares, algunas de ellas enciclopédicas, así como pistas perdidas, que en un momento dado entorpecen el objetivo de acceder al compendio. Si bien es cierto que se incluyen tecnicismos y extranjerismos, muchos de ellos no se ajustan a la realidad de los usuarios ni mucho menos a sus necesidades, olvidando el tipo de destinatario para quien fue elaborado. El uso generalizado de letra cursiva no permite claridad en torno a la diferenciación entre ejemplos y expresiones, creando confusión al momento de poder discernir sobre los lemas que se están buscando.

\section{Diccionario Escolar llustrado Color, DEIC}

1

2

3

4

5 explicaciones didácticas suficientes sobre su uso e ilustraciones iniciales que puedan atraer al usuario potencial del diccionario. Es decir, algunas características externas pueden mejorarse en relación con el carácter didáctico y el tipo de lector al que está dirigido.

Según la información dada en la cubierta, se incluyen más de 25.000 entradas, pero este número no corresponde con el promedio realizado entre número de páginas y el conteo de entradas por cada una de ellas. En la presentación se afirma la inclusión de un vocabulario variado de neologismos, tecnicismos, extranjerismos y americanismos, pero en el corpus no se evidencian algunos de uso frecuente. Se registran muchas voces cultas o alejadas del contexto escolar de uso, además de españolismos plenos.

Las entradas se diferencian tipográficamente del resto de los contenidos. Se lematiza en orden alfabético y se marca silábicamente la flexión de género. En el caso de femeninos irregulares, éstos aparecen marcados en el mismo lema o se registran como una entrada aparte. Los términos homónimos se lematizan de manera independiente y se establecen lemas dobles cuando se presentan variaciones de acentuación.

Dibujos y fotografías a color a razón de una o dos por página en el cuerpo del diccionario. Algunas fotografías registran objetos y

9 eventos cotidianos. Sin embargo, en muchos casos se ilustran términos innecesariamente. Como apéndice se presentan mapas de Colombia y banderas, además de dibujos que solamente representan sistemas geológicos y fisiológicos.

El vocabulario no se ajusta en su totalidad a las características del usuario potencial, aparecen muchos términos cultos, peninsulares y no se incluyen voces coloquiales suficientes, es decir, se pone en riesgo el criterio de uso, el cual aleja al lector de los contextos en los que se encuentra inmerso. De igual manera, las ilustraciones que se registran al final no exploran suficientes entornos de aprendizaje.

Algunas definiciones carecen de claridad y se tornan incomprensibles. Se evidencian casos de "pistas perdidas" y también definiciones circulares y enciclopédicas. No se emplean contornos de definición, en su lugar se emplean algunas abreviaturas.

Según la información dada en la cubierta, existen más de 80.000 acepciones, las cuales se separan una de otra a través de números y puntos. Aun cuando la tendencia es ir de la acepción más general a la más específica, éste criterio se obvia en algunas casos. Se registran acepciones que no se corresponden con la realidad de uso del lector o se excluyen algunas de uso frecuente.

Hay muy pocos ejemplos. Los que se registran, aparecen en letra cursiva y no cumplen la función de complementar información dada en la definición o en ciertos usos verbales. Por consiguiente, se pone en riesgo el carácter didáctico del diccionario.

Se emplean marcas gramaticales básicas para diferenciar tipos de verbos, sustantivos, adverbios, pronombres y conjunciones. No hay explicaciones gramaticales sobre verbos irregulares o ciertos usos gramaticales específicos que puedan ser de utilidad al lector. 
Sólo se evidencia de manera asistemática la marca familiar y, en algunos casos aislados la vulgar, para delimitar contextos de uso. Lo anterior puede desinformar al usuario sobre elementos pragmáticos que debe tener en cuenta. Se registran también marcas diatópicas de América Central y meridional y de algunos países centroamericanos y latinoamericanos, sin embargo, este tipo de información no es fundamental en un diccionario escolar y, además, amerita un ejercicio de contrastación más amplio. Por último, se halla la marca estilística para señalar sentidos figurativos.

Pese a presentar marcas sobre expresiones en las partes introductorias, éstas no se registran en el cuerpo del diccionario.

No se presentan sinónimos ni antónimos.

Existe una escasa información etimológica, solamente en casos de extranjerismos.

No hay apéndices relacionados con información gramatical o contextual. Se evidencian algunos mapas de Colombia, banderas de países, dibujos, sistemas fisiológicos y explicaciones geológicas. Por tanto, no se emplea este mecanismo para complementar o aligerar la información dada en el cuerpo del diccionario.

Se registran valoraciones subjetivas en definiciones. Asimismo, algunas fotografías muestran objetos con marcas comerciales o alusivos a ciertos emblemas de países.

20 Carece de una guía didáctica.

Algunos criterios que ponen en riesgo la orientación didáctica de este diccionario escolar se relacionan con la ausencia de ejemplos, marcas de uso, sinónimos y antónimos y, en general, de informaciones que permitan enriquecer en el usuario su expresión oral y escrita, así como su conocimiento sobre diversos contextos de su actuación lingüística.

\section{Diccionario Didáctico Escolar sm.}

$1 \quad$ Empaste plastificado flexible y cosido. Tiene un tamaño y volumen adecuados para ser transportado a cualquier lugar.

En el título se señala que es un tipo de diccionario didáctico escolar, didec. Se registra el nombre de la editorial. Se especifica el grado de enseñanza de sus usuarios potenciales.

3 Ediciones sm.

El proyecto editorial está cargo de dos personas. De igual forma se registran los miembros de la coordinación editorial, del editor

4 y del equipo de redacción; del diseñador de la portada, de los diagramadores y la gestión informática, lo que evidentemente muestra un trabajo ejecutado por un amplio equipo de lexicógrafos.

Registra un prólogo y luego una página dedicada a la presentación, en la que menciona las características generales del diccionario. Allí se destaca el hecho de que éste sea el primer compendio escolar que se ha adaptado a las necesidades específicas de los estudiantes de primaria de Colombia. De igual forma, trae una serie de informaciones didácticas en torno a los interrogantes sobre qué es el diccionario y cuál es su función. izquierdo y derecho de las páginas se registra la primera y la última entrada, respectivamente.

Es un diccionario de un volumen apropiado; con un muy buen tamaño de letra y el uso del color para diferenciar las entradas de las acepciones. Además, la inclusión de la presentación propone lo que un usuario puede encontrar en él, lo que constituye una orientación muy valiosa para el estudiante.

$7 \quad$ En la presentación del diccionario se hace mención a la inclusión de palabras actuales y frecuentes en el español de Colombia. Contiene 17.000 entradas, 26.000 definiciones aproximadamente. Tiene 735 páginas.

8 Las entradas se diferencian tipográficamente del resto de los contenidos. Se lematiza en orden alfabético y se marca silábicamente la flexión de género. Los términos homónimos no se lematizan de manera independiente.

Este diccionario cuenta con una serie de ilustraciones, específicamente 32 ilustraciones a color y 274 a blanco y negro. Además, presenta una serie de encartes que incluyen instrumentos musicales, monumentos turísticos, frutas, herramientas,

9 animales, estados de ánimo, profesiones, pisos térmicos y el mapa físico y político de Colombia. Cabe señalar que se utiliza una forma de señalización Ilamada "ojo con patas", que indica la remisión a la página en la que hay una ilustración que hace referencia a la acepción donde está la señal.

Una de las grandes ventajas que ofrece este diccionario es la inclusión de palabras del español de Colombia, lo que permite al estudiante de básica primaria conocer de manera más clara la denominación de realidades próximas, pero cuyo nombre desconoce. Por otra parte, la inclusión de ilustraciones relacionadas con elementos propios de Colombia es muy valiosa en tanto sugiere una verdadera ampliación del sentido contenido en las acepciones.

Las definiciones son sencillas, cortas y comprensibles para el usuario al que está dirigido (ocho a doce años, colombiano). Se logra una redacción con un vocabulario mínimo definidor y con modelos sencillos para definir términos de un mismo campo semántico. No se evidencian "pistas perdidas" ni definiciones circulares. 
Las acepciones aparecen organizadas según órdenes específicos y a la vez homogéneos en el diccionario. Se incluyen acepciones usuales. Además, éstas se separan con números que se resaltan en el artículo lexicográfico.

Hay bastantes ejemplos (14.000 aproximadamente) que aclaran y precisan la definición y, además, proporcionan información sobre el uso gramatical. Éstos son variados y evidencian, además de una realidad de uso, un vocabulario que se encuentra en el diccionario.

Se presentan marcas gramaticales de fácil comprensión y, además, información en corchetes que orienta al lector sobre ciertos usos gramaticales, como conjugaciones verbales, formas femeninas y masculinas, plurales, etc. Además, se utiliza en el artículo lexicográfico un tipo de signo que le indica al lector el cambio de categoría gramatical. Es ilustrativo, además, encontrar en el cuerpo del diccionario cuadros explicativos de conjugación verbal.

Incluye una variada información entre corchetes sobre pronunciación, ortografía y registros de uso. En general, este compendio de informaciones le da al lector seguridad para el uso de los términos en diferentes contextos. Por otra parte, después de cada lema se presenta su correspondiente partición silábica y acentuación.

Se incluyen aproximadamente 1.323 locuciones, las cuales se localizan al final de artículo. Éstas son usuales y se acompañan de anotaciones pragmáticas. Por consiguiente, el usuario logra enriquecer su vocabulario.

En varias acepciones se proponen sinónimos y antónimos, los cuales se ubican en la parte final del artículo. Este tipo de información se propone sólo cuando es necesario. De igual manera, se presentan familias de palabras en las que se diferencian las palabras primitivas de las derivadas. Por tanto, el lector del diccionario accede a un repertorio léxico más amplio, necesario para su función de codificación.

No se registran etimologías. En algunos casos se ofrece información sobre términos que proceden de marcas comerciales o de lenguas extranjeras.

No se registra. En su lugar, hay, en la mitad del diccionario, un conjunto de encartes a color.

Se intenta mantener una imparcialidad en la construcción de definiciones, ejemplos e ilustraciones, aun cuando se incluye vocabulario correspondiente a campos históricos y políticos que forman parte de la realidad colombiana.

Se acompaña de una guía didáctica elaborada con rigurosidad en la que se pueden llevar a cabo varios ejercicios que le permiten al usuario aprovechar el diccionario en todas sus dimensiones.

Es un diccionario que evidencia un tratamiento didáctico en relación con la presentación de los contenidos. Además, desde sus elementos microestructurales, establece constantemente informaciones valiosas con respecto al uso de los términos y una vinculación al contexto real al que pertenece el destinatario. Por consiguiente, es una propuesta novedosa que hace explícita la experiencia y asesoría en las áreas editorial, escolar y lexicográfica.

\section{Bibliografía}

Ediciones Larousse. (2007). Diccionario Escolar Larousse (primera edición). México.

Ediciones SM. (2008). Diccionario Didáctico Escolar, didec. Bogotá.

Garriga, C. (2002). Los diccionarios escolares [versión electrónica]. Revista Textos, 31.

Grupo Editorial Norma. (2004). Diccionario Escolar Ilustrado Color. Lima, Perú.

Henríquez, M. C. (2002). La importancia del uso del diccionario en la enseñanza de la lengua: Conferencia. I Congreso de Lectoescritura. Unad, marzo 15-16.

Hernández, H. (1989). Los diccionarios de orientación escolar. Lexicographica. Series Maior, 28. páginas.

Hernández, H. (2000). Últimas tendencias en lexicografía didáctica. En Tendencias en la investigación lexicográfica del español. El diccionario como objeto de estudio lingüístico y didáctico. Huelva: Universidad de Huelva Publicaciones.
Maldonado, C. (2000). Criterios para elegir un diccionario. En: Tendencias en la investigación lexicográfica del español. El diccionario como objeto de estudio lingüístico y didáctico. Huelva: Universidad de Huelva Publicaciones.

Martínez, J. (s. f.). Los diccionarios escolares del español: lo que son y lo que deberían ser. En I., Ahumada (1991), Diccionarios españoles: contenidos y aplicaciones. Lecciones del I Seminario de lexicografía hispánica. Facultad de Humanidades, Jaén.

Medina, A. (2003). Lexicografía española. Barcelona: Ariel.

Porto, A. (2002). Manual de técnica lexicográfica. Madrid: Arco Libros.

Prado, J. (2000). El diccionario y la enseñanza de la lengua. En Tendencias en la investigación lexicográfica del español. El diccionario como objeto de estudio lingüístico y didáctico. Huelva: Universidad de Huelva Publicaciones. 